\title{
Incentive Mechanism Design Aiming at Deflated Performance Manipulation in Retail Firms: Based on the Ratchet Effect and the Reputation Effect
}

\author{
Biao Luo, Chengyuan Wang, and ChunYi Li \\ The School of Management, University of Science and Technology of China, Hefei, Anhui 230026, China \\ Correspondence should be addressed to Chengyuan Wang; nanjing@mail.ustc.edu.cn
}

Received 2 March 2016; Accepted 23 August 2016

Academic Editor: Roman Wendner

Copyright (C) 2016 Biao Luo et al. This is an open access article distributed under the Creative Commons Attribution License, which permits unrestricted use, distribution, and reproduction in any medium, provided the original work is properly cited.

\begin{abstract}
Store managers in retail firms are often offered a performance-based compensation scheme accompanied with a performance target by the headquarters. The headquarters adjusts the performance target based on store managers' historical performance and therefore generates the ratchet effect. Consequently, store managers may downward manipulate performance, that is, deflated performance manipulation, so as to weasel out of target growth and smooth performance growth. However, the reputation effect that seeks fame by store managers can restrain deflated performance manipulation. We model a dynamic agency setting in which both the ratchet effect and the reputation effect are related to the store manager's compensation scheme, and the store manager has to balance her effort and deflated performance manipulation. Our findings reveal that the ratchet effect and environmental volatility jointly determine the existence of deflated performance manipulation, yet the reputation effect can restrain it with increasing environmental volatility. In addition, deflated performance manipulation is inevitable when environmental volatility is large enough, and explicit incentives may promote deflated performance manipulation.
\end{abstract}

\section{Introduction}

In retail firms, the headquarters has to motivate and supervise multiple stores. In order to enhance the performance per store, the headquarters always offers store managers a performance-based compensation scheme [1]. The compensation scheme is generally comprised of a fixed component and a revenue sharing and therefore binds the store managers' compensation to their performance [2]. In addition, the compensation scheme is often followed by a performance target which acted as a criterion to evaluate the store manager's performance. For the headquarters, such scheme seems to be an ideal arrangement to motivate store managers to make every effort. In fact, however, the scheme often generates side-effect, that is, the ratchet effect. Due to asymmetric information and lacking market insights relative to the store manager, the headquarters often sets the target on the basis of the store manger's historical performance. The high historical performance will lead to the high current target, and the circulation scrolls up by such analogy in the future fiscal years. The ratchet effect has been verified in practice by a series of empirical evidence, for example, [3-6].

Store managers can be naturally conscious of the ratchet effect, and they generally take two measures, that is, intentional reducing effort or lowering the reported performance, to evade the pressure produced by the growing performance target. Regarding managers' such adverse selections, prior agency studies mainly focused on the former, that is, investigating how to avoid effort reduction by managers (e.g., $[7,8])$. Conversely, shrewd store managers often adopt the latter in practice. It is because lowering reported performance not only can lead the headquarters to set a moderate target in the next period, but also implies a portion of surplus performance that can be counted in the next period, so as to ensure a smooth performance growth. We defined such manipulative behavior that managers virtually downward reduce performance as deflated performance manipulation. It leaves some regulatory leeway for store managers to adjust performance in the next period, in order to maximize their interperiod incomes. Given that deflated performance manipulation is 
widely common in practice, it is very necessary to investigate how store managers manipulate performance to oppose the ratchet effect.

In addition, store managers will also restrain themselves out of seeking reputation, that is, reputation effect. It is because deflated performance manipulation may not violate the law but is always accompanied by moral hazard. In addition, social reputation can be conducive to enhance store managers' bargaining power in compensation negotiation. Yet once the manipulation is ferreted out, the store manager might fall into disrepute in the eyes of the headquarters, as well as in the labor market. Fama [9] pointed out that, in a long-term incentive setting, social reputation can be an implicit incentive to restrain managers' misconduct.

Given that the ratchet effect and the reputation effect have opposite impacts on store managers, in this paper, we focus on studying how the two effects jointly influence the performance manipulation of the store manager, who is given a performance-based compensation scheme, and the optimal incentive. Due to both the ratchet effect and the reputation effect referring to long-term incentive problem, we model a dynamic agency setting to investigate how the store manager balances her effort involvement and deflated performance manipulation, so as to help the headquarters improve the incentive scheme and supervision.

This paper contributes to the agency literature in twofold. First, we bridge the research gap between the ratchet effect and deflated performance manipulation that was ignored by prior studies. We embody the relationship between the ratchet effect and deflated performance manipulation in a dynamic agency setting. Second, we jointly consider the different impacts of two effects, that is, ratchet effect and reputation effect, on the store manager's behaviors and the optimal incentive. The jointly incorporating such two effects can provide a better dialogue with prior studies.

The remainder of the paper is organized as follows. Section 2 provides a review of the literature. We construct the analysis model in Section 3. We give the cross-sectional results of the model in Section 4. Implications of our results and concluding remarks are given in Section 5.

\section{Literature Review}

To align store managers' salary with their performance, the headquarters of retail firms always offers a performancebased compensation scheme to store managers [1]. However, an unanticipated result is that, in more cases, store managers tend to manipulate the reported performance rather than make more efforts. Abundant evidence has demonstrated store managers' performance manipulation. For instance, Healy [10] found that if the bonus reward based on performance is an important part of managers' compensation, they will be motivated to handle actual profits to increase their compensation. Further researches [11-13] had also verified the relationship between the bonus plan and performance manipulation and found that store managers often manipulate performance so as to transfer wealth from the principle to them. These studies focused on a static agency setting in which managers tend to upward manipulate reported performance. In a dynamic agency setting, however, performance manipulation of store managers may be more complicated.

Recently, the incentive scheme involved with the performance manipulation has been extensively studied. Crocker and Morgan [14] investigated misreporting in a principalagent setting. Goldman and Slezak [15] developed an agency model which shows that a stock-based compensation can not only induce managers to make productive effort but also divert valuable resources to misrepresent performance. Burns and Kedia [16] tested the effect of compensation scheme on managers' misreporting and found that stock options are associated with stronger incentives to misreport. Crocker and Slemrod [17] characterized the optimal compensation scheme in the setting where managers may take actions to hide actual performance information and demonstrated that a compensation scheme contingent on reported earnings neither promotes managers to maximize profits nor leads managers to report actual profits honestly.

Among various forces that impact store manager's performance manipulation in a dynamic agency setting, there are two important effects that can oppositely influence store managers' tendency to manipulate performance. One is the ratchet effect, which is widespread in retail firms and unexpectedly induces store managers to downward manipulate reported performance, that is, deflated performance manipulation as we defined. The ratchet effect derives from the growing performance target accompany with performancebased compensation scheme. The headquarters always sets current target based on the store manager's historical performance, and therefore the higher historical performance leads to the higher target and vice versa $[5,7,18]$. Consequently, store managers are inclined to reduce current performance to lessen the pressure of a higher target in the next period. Regarding reducing current performance, calculative managers often balance effort reduction and deflated performance manipulation. It is because the latter can help store managers use the unreported surplus performance to smooth performance in the next period, for example, earnings management $[1,19-21]$, so as to guarantee seemly performance growth. Goal-setting theory provides evidence to explain the reason that managers tend to take risk to attain a high target [22]. Leone and Rock [23] suggested that managers are promoted to manipulate reported earnings downward by accruals. Other scholars also suggested that managers will reduce their actual performance by various ways, for example, allowing for price discounts [24] and reducing investments [25, 26], because deflated performance manipulation is concealed and is difficult to be perceived [8].

The other one is the reputation effect, which can restrain store managers' manipulation. The reputation can enhance store managers' bargaining power in compensation negotiation with the headquarters as well as in external executive labor market and therefore will promote store managers to make more effort. The rudiment of the reputation effect derives from Fama's [9] work which proposed that the labor market appropriately uses current and past information to revise future wages. Holmstrom [27] modeled the proposition of Fama [9] and suggested that incentive problems, 
at least in part, can be eased through the role of longterm reputation in a dynamic environment. Meyer and Vickers [28] analyzed the comparative performance model with introducing historical performance and showed that the role of the reputation effect is opposite with the ratchet effect. In order to maximize the total utility, the headquarters must be able to predict what the store manager will do [29] when the reputation is an effective information for prediction [30]. Accordingly, store managers can legitimately require a better compensation by the contract negotiation. Thus, the reputation effect is considered in our model and plays a role by adjusting the fixed wage in the compensation contract.

We jointly consider the ratchet effect and the reputation effect in this paper, in order to investigate how store managers under the two different effects will balance this effort involvement and the extent of performance manipulation, and help the headquarters design the optimal incentive on the basis of the participation constraint.

\section{Model Development}

We consider the following agency setting. In a retail firm, the headquarters hires a manager to operate a branch store over two periods when the first period is the start-up and the second period is the final one. The headquarters offers a performance-based compensation scheme accompany with a sales target for the manager [31-34]. The compensation scheme is a linear contract which has an explicit formula showing clearly the tradeoff between risk-sharing and incentives [35]. Holmstrom and Milgrom [36] considered the optimality of the linear contract in a natural class of dynamic moral hazard problems. Thus, we draw the following linear schemes.

Assumption 1 (a performance-based compensation scheme). The output of period $i$ is $\pi_{i}$ and the corresponding performance target is $\underline{\pi}_{i}$. The manager's incomes derive merely from her compensation which is linear decided by her output:

$$
s_{i}\left(\pi_{i}\right)=\alpha_{i}+\beta\left(\pi_{i}-\underline{\pi}_{i}\right) \quad(i=1,2),
$$

where $\alpha_{i}$ and $\beta$ are parameters of the linear contract given by the headquarters. Therein, $\alpha_{i}$ is the fixed wage in the period $i$. As previously mentioned, the fixed wage in the second period may be changed following the manager's reputation. However, the pay-for-performance sensitivity $\beta$ is changeless and $0 \leq \beta \leq 1$. Thus, $\beta\left(\pi_{i}-\underline{\pi}_{i}\right)$ is the incentive bonus related to surplus performance, which is the actual performance minus performance target.

Following prior studies $[27,37,38]$, we consider that the store manager's output is linear decided by her effort and talent. Since the profitability of the store is an important factor to the output, we take it into account in our model and therefore draw the following assumption.

Assumption 2. The actual output is given by

$$
\pi_{i}=\lambda a_{i}+\eta+\varepsilon_{i}
$$

where $\lambda>0$ is the profitability of the store, $\eta \sim N\left(0, \tau \sigma^{2}\right)$ is the manager's talent, and $\varepsilon_{i} \sim N\left(0,(1-\tau) \sigma^{2}\right)$ is the random variables due to exogenous environmental volatility. Though the store manager chooses the effort $a_{i}$, the headquarters who can just observe the report output $\tilde{\pi}_{i}$ does not know the real level of $\eta$ and $\varepsilon_{i}$. We assume that $\operatorname{cov}\left(\varepsilon_{1}, \varepsilon_{2}\right)=0$ and

$$
\tau=\frac{\operatorname{var}(\eta)}{\operatorname{var}(\eta)+\operatorname{var}\left(\varepsilon_{i}\right)},
$$

and thus we have $\operatorname{var}\left(\pi_{i}\right)=\sigma^{2}$.

There is a cost $C\left(a_{i}\right)$ to exert an effort $a_{i}$. The effort cost is concave and therefore $C^{\prime}\left(a_{i}\right)>0$ and $C^{\prime \prime}\left(a_{i}\right)>0[33,39]$. For more analytical results as prior studies did (e.g., [40, 41]), we assume the following.

Assumption 3. The store manager's effort cost is

$$
C\left(a_{i}\right)=\frac{b}{2} a_{i}^{2}
$$

where $b>0$ is the effort cost coefficient.

The general problem faced by the headquarters is information asymmetry, because the store manager can influence the reported performance output.

Assumption 4. If the manager manipulates the reported performance, which will be given by

$$
\tilde{\pi}_{i}=\pi_{i}-\Delta \pi_{i}=\lambda a_{i}+\eta+\varepsilon_{i}-\Delta \pi_{i}
$$

where $\Delta \pi_{i}$ denotes the extent of deflated performance manipulation, according to (5), in each period, the store manager has to balance her effort $a_{i}$ and deflated performance manipulation $\Delta \pi_{i}$ in order to maximize her utility across the interperiod. Hence, the expected value of $\tilde{\pi}_{i}$ is given by $E\left(\tilde{\pi}_{i}\right)=\lambda a_{i}-\Delta \pi_{i}$.

In retail firms, the headquarters always uses each store's annual deviation from its current sales target to set next year's sales target. The store manager has more motivation to manipulate to reduce the current performance in order to lessen the pressure of the next year higher target. We assume that the manager only chooses the deflated performance manipulation, and thus

$$
\Delta \pi_{i}=\pi_{i}-\tilde{\pi}_{i} \geq 0 .
$$

This part of output $\Delta \pi_{i}$ can be achieved later in next year by accounting means.

Considering the manager may manipulate the reported performance, the headquarters may supervise the manager. And thus, we draw the following.

Assumption 5. The headquarters supervises the reported performance of stores and learns whether the store manager manipulates with some probability $\gamma(0<\gamma<1)$ which indicates the effectiveness of the supervision. To bind the manager's behaviors, we consider the punishment setting 
following the effort cost $C\left(a_{i}\right)$. The punishment $C_{p}$ is also concave (i.e., $C_{p}^{\prime}>0$ and $C_{p}^{\prime \prime}>0$ ). For more analytic results, the punishment for manipulation is given by

$$
C_{p}=\frac{k}{2} \Delta \pi_{i}^{2}
$$

where $k>0$ is the punishment coefficient. Thus, the expected punishment of the manipulation is $\gamma C_{p}$.

Hart and Holmstrom [37] argued that the manager should be risk-neutral in a dynamic setting. Accordingly, we put forward the following.

Assumption 6. The headquarters and the store manager are both risk-neutral.

Because the external environment and the investment of headquarters to store have no significant change, the performance target is generally based on historical performance. On the other side, the ratchet effect leads to higher target in next period if current performance is higher than the historical level and vice versa. Because the headquarters hires the manager in the first period when the talent of the manager is unknown, let $\underline{\pi}_{1}=0$ denote the performance target of the first period, and let the difference between real output and target (i.e., $\pi_{1}-\underline{\pi}_{1}$ ) denote the deviation of the expected performance. Based on adaptive expectation theory, the target in next period will be adjusted according to the deviation. We assume that the target of the second period is given by

$$
\underline{\pi}_{2}=\underline{\pi}_{1}+h\left(\pi_{1}-\underline{\pi}_{1}\right)=h \pi_{1},
$$

where $h>0$ is the target adaptation coefficient which reflects the adjustment of the next target according to the ratchet effect. However, the store manager can manipulate performance to achieve private interests by the role of $a_{1}$ and $\Delta \pi_{1}$ which can change $\tilde{\pi}_{1}$.

Based on the reputation effect, the store manager' effort and manipulation not only affect the current compensation but also affect the future reputation. According to Assumption 2, though the manager's talent is private information, but it can be evaluated by the headquarters based on the past performance. The headquarters will evaluate the store manger's talent by the observation of historical performance while the store manager can affect such expectation by her effort $a_{1}$ and manipulation $\Delta \pi_{1}$. Suppose $\widehat{a}_{1}=E\left(a_{1}\right)$ is the headquarters expectation about the store manager's effort. Having observed the output $\pi_{1}$, the headquarters will learn $\eta+\varepsilon_{1}=\pi_{1}-\lambda \widehat{a}_{1}$ while it cannot separate $\eta$ from $\varepsilon_{1}$. The headquarters has to infer $\eta$ according to $\pi_{1}$. On the basis of rational expectation theory, for a given $\pi_{1}$, the expected ability of the store manager $E\left(\eta \mid \pi_{1}\right)$ is equal to the weighted average of the priori value $E(\eta)$ and the a posteriori observed value $\left(\pi_{1}-\lambda \widehat{a}_{1}\right)$. Correspondingly, the expected ability of the store manager is given by

$$
\begin{aligned}
E\left(\eta \mid \pi_{1}\right) & =(1-\tau) E(\eta)+\tau\left(\pi_{1}-\lambda \widehat{a}_{1}\right) \\
& =\tau\left(\pi_{1}-\lambda \widehat{a}_{1}\right) .
\end{aligned}
$$

And if the headquarters can only observe the reported output,

$$
E\left(\eta \mid \tilde{\pi}_{1}\right)=\tau\left(\tilde{\pi}_{1}-\lambda \widehat{a}_{1}\right),
$$

where $\widehat{a}_{1}$ denotes the headquarters' expected value on the store manger's effort. Based on the supervision and the manipulation, the expected ability of the store manager is given by

$$
\begin{aligned}
\gamma E & \left(\eta \mid \pi_{1}\right)+(1-\gamma) E\left(\eta \mid \widetilde{\pi}_{1}\right) \\
& =\tau\left[\lambda a_{1}+\eta+\varepsilon_{1}-(1-\gamma) \Delta \pi_{1}-\lambda \widehat{a}_{1}\right] .
\end{aligned}
$$

The reputation effect plays a role by adjusting the fixed wage in the compensation scheme; that is,

$$
\alpha_{2}=\alpha_{1}+c\left[\gamma E\left(\eta \mid \pi_{1}\right)+(1-\gamma) E\left(\eta \mid \tilde{\pi}_{1}\right)\right],
$$

where $c \geq 0$ is the bargaining power coefficient of the store manager. The higher the bargaining power coefficient is, the more important the role that the reputation mechanism plays. The reputation effect and the ratchet effect are both reflected in the following formula:

$$
\begin{aligned}
s_{2}\left(\pi_{2}\right)= & \alpha_{2}+\beta\left(\pi_{2}-\underline{\pi}_{2}\right) \\
= & \alpha_{1}+c\left[\gamma E\left(\eta \mid \pi_{1}\right)+(1-\gamma) E\left(\eta \mid \tilde{\pi}_{1}\right)\right] \\
& +\beta\left[\pi_{2}-h\left(\gamma \pi_{1}+(1-\gamma) \tilde{\pi}_{1}\right)\right] .
\end{aligned}
$$

The second period is the final period, and hence the output of the second period will not affect the future compensation of the store manager. In the second period, the manager will maximize the current compensation. On the contrary, the managerial effort and the manipulation in the first period can affect the current and future compensation. Thus, in the first period, the manager has to consider the total revenue over two periods. The game order between the headquarters (the principle) and the store manager (the agent) is (1) the headquarters first determines the contract of the first period (i.e., the fixed wage $\alpha_{1}$ and the pay-forperformance sensitivity $\beta$ ); (2) the store manager makes an effort $a_{1}$ based on the contract and produces the real output $\pi_{1}$ which is her privacy information. However, the headquarters can discover the real output with some possibility $\gamma$ or only get the reported output $\widetilde{\pi}_{1} ;(3)$ the headquarters adjusts the contract of the second period (i.e., the fixed wage $\alpha_{2}$ and the target $\underline{\pi}_{2}$ ) based on historical performance of the first period; and (4) the store manager chooses her effort $a_{2}$ and the reported output $\tilde{\pi}_{2}$. The timing of the principal-agent game is shown in Figure 1.

Utility functions of the headquarters (i.e., $U_{H 1}$ and $U_{H_{2}}$ ) and the store managers (i.e., $U_{M 1}$ and $U_{M 2}$ ) in each period are given by

$$
\begin{aligned}
U_{H 1} & =E\left(\pi_{1}-\gamma s_{1}\left(\pi_{1}\right)-(1-\gamma) s_{1}\left(\widetilde{\pi}_{1}\right)+\frac{\gamma k}{2} \Delta \pi_{1}^{2}\right), \\
U_{M 1} & =E\left(\gamma s_{1}\left(\pi_{1}\right)+(1-\gamma) s_{1}\left(\widetilde{\pi}_{1}\right)-\frac{\gamma k}{2} \Delta \pi_{1}^{2}\right. \\
& \left.-\frac{b}{2} a_{1}^{2}\right),
\end{aligned}
$$




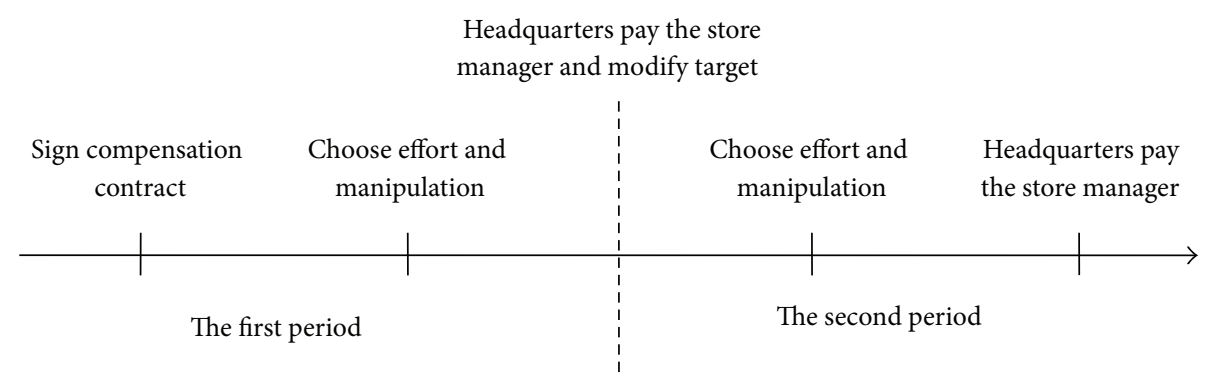

FIGURE 1: The dynamic (two-period) principal-agent problem.

$$
\begin{aligned}
U_{H 2} & =E\left(\pi_{2}-\gamma s_{2}\left(\pi_{2}\right)-(1-\gamma) s_{2}\left(\tilde{\pi}_{2}\right)+\frac{\gamma k}{2} \Delta \pi_{2}^{2}\right. \\
& \left.-(1-\gamma) \beta \Delta \pi_{1}\right), \\
U_{M 2} & =E\left(\gamma s_{2}\left(\pi_{2}\right)+(1-\gamma) s_{2}\left(\tilde{\pi}_{2}\right)-\frac{\gamma k}{2} \Delta \pi_{2}^{2}-\frac{b}{2} a_{2}^{2}\right. \\
& \left.+(1-\gamma) \beta \Delta \pi_{1}\right) .
\end{aligned}
$$

The modified agency model with manipulation is

$$
\begin{array}{ll}
\max _{\beta} & U_{H 1}+\delta U_{H 2} \\
\text { S.t. } & \mathrm{IR} U_{M 1}+\delta U_{M 2} \geq \underline{U} \\
& \mathrm{IC}_{1} a_{2}^{*}=\arg \max U_{A 2} \\
& \mathrm{IC}_{2} \Delta \pi_{2}^{*}=\arg \max U_{A 2} \\
& \mathrm{IC}_{3} a_{1}^{*}=\arg \max U_{A 1}+\delta U_{A 2} \\
& \mathrm{IC}_{4} \Delta \pi_{1}^{*}=\arg \max U_{A 1}+\delta U_{A 2},
\end{array}
$$

where IR is the participation constraint of the store manager, in which the manager's expected utility should be larger than her reservation utility $\underline{U}$. The incentive compatibility constraints (i.e., $\mathrm{IC}_{1}$ and $\mathrm{IC}_{2}$ ) show that the store manager will choose $a_{2}$ and $\Delta \pi_{2}$ to maximize her expected utility of the second period. From the incentive compatibility constraints (i.e., $\mathrm{IC}_{3}$ and $\mathrm{IC}_{4}$ ), the store manager chooses $a_{1}$ and $\Delta \pi_{1}$ to maximize her total expected utility over two periods. We also consider the time discount aims at intertemporal gains, and therefore $\delta<1$ denotes the discount factor.

Different from traditional agency models [33], we first add incentive compatibility constraints of the performance manipulation into our model. Second, we assume that the headquarters goes after both increasing effort $a_{i}$ and reducing manipulation $\Delta \pi_{i}$. Finally, considering the long-term implicit incentive effect, the store manager will weigh against the current income and long-term gains.

From the above, the manager's optimal effort of the second period according to $\mathrm{IC}_{1}$ is given by

$$
a_{2}^{*}=\frac{\beta \lambda}{b} \text {. }
$$

This result is consistent with traditional agency models [33], because the store manager does not need to consider the long-term implicit incentive in the last period. Based on $\mathrm{IC}_{2}$, the manager's optimal manipulation in the second period is given by

$$
\Delta \pi_{2}^{*}=0
$$

In the second period, deflated performance manipulation cannot increase private interests through the ratchet effect, such that the manipulation is inadvisable in this period. According to $\mathrm{IC}_{3}$ and $\mathrm{IC}_{4}$, the optimal effort and the optimal manipulation in the first period are given by

$$
\begin{aligned}
a_{1}^{*} & =\frac{\lambda[(1-h \delta) \beta+c \tau \delta]}{b}, \\
\Delta \pi_{1}^{*} & =\frac{(1-\gamma)[(h \delta+\delta-1) \beta-c \tau \delta]}{\gamma k} .
\end{aligned}
$$

The optimal effort in the first period depends on not only the pay-for-performance sensitivity, but also the target adaptation coefficient $h$ and bargaining power coefficient $c$. In (18) and (19), $c \tau \delta$ implies the reputation effect which promotes the store manager to work hard, while $\beta h \delta$ implies the ratchet effect which leads the store manager to reduce effort.

The equilibrium of the pay-for-performance sensitivity is set so as to balance the net benefit from inducing effort and the cost of inducing manipulation. With the optimal effort and the optimal manipulation above, the optimal pay-forperformance sensitivity is given by

$$
\begin{aligned}
& \beta^{*} \\
& =\frac{\lambda^{2} \gamma k[\delta+(1-h \delta)(1-2 c \tau \delta)]+b c \tau \delta(1-\gamma)^{2}(\delta h+\delta-1)}{2 \lambda^{2} \gamma k\left[(1-h \delta)^{2}+\delta\right]+b(1-\gamma)^{2}(\delta h+\delta-1)^{2}} .
\end{aligned}
$$

\section{Cross-Sectional Results}

This section develops a set of cross-sectional implications that predict how the manager's manipulation and effort vary with the pay-for-performance sensitivity and observable firm characteristics which are replaced by parameters in the model. Proofs are provided in Appendix. 


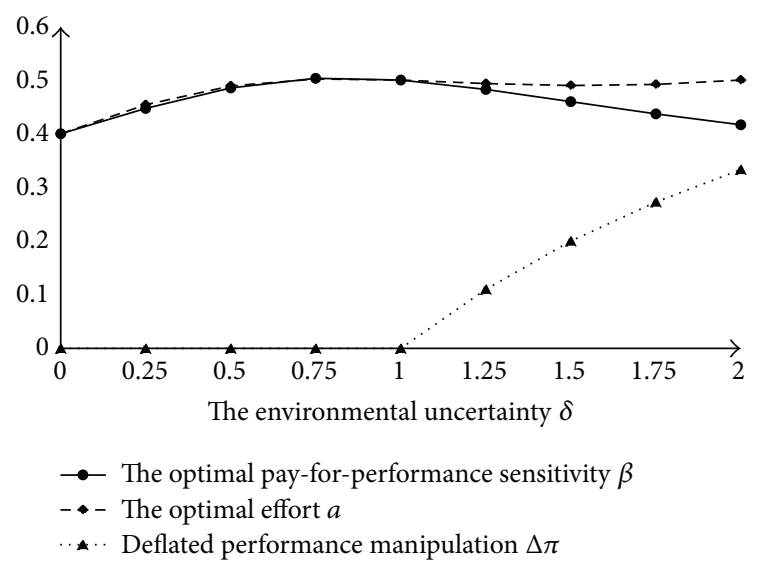

(a) The case that the target adaptation coefficient is equal to 0.5 ( $h=$ $0.5)$

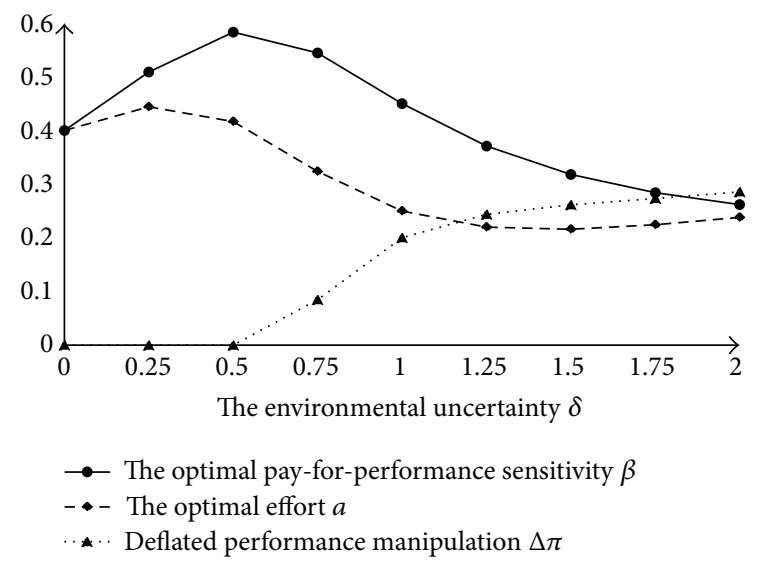

(b) The case that the target adaptation coefficient is equal to $1(h=$ 1)

FIGURE 2: Numerical simulations in different levels of the target adaptation coefficient and the environmental volatility. (Note that other parameters are given by $\lambda=1, \gamma=0.5, \tau=0.5, k=1, b=1$, and $c=0.5$.)

\subsection{Optimal Manipulation Implications}

Proposition 7. There exists a nonempty set of parameters $\delta h+\delta-1<0$ under which the store manager will not manipulate performance no matter what the pay-forperformance sensitivity $\beta$ is. On the contrary, if $\delta h+\delta-1>0$ and the pay-for-performance sensitivity satisfies

$$
\beta>\frac{c \tau \delta}{h \delta+\delta-1},
$$

the extent of manipulation $\Delta \pi_{1}^{*}>0$ which is showed in (19).

Proposition 7 suggests that the existence of deflated performance manipulation is contingent on two variables, that is, the target adaptation coefficient $h$ and environmental volatility $\delta$. According to $\delta h+\delta-1<0$, the store manager will never choose to manipulate performance when $h<$ $1 /(\delta+1)$. In addition, the larger environmental volatility $\delta$ means the lower target adaptation coefficient $h$ that the headquarters should adopt. Accordingly, when facing a stable market circumstance (i.e., a small $\delta$ ), the headquarters can remain at a certain level of the target adaptation coefficient $h$ to motivate the store manager. Conversely, the store manager may inevitably manipulate performance when facing high environmental volatility. Thus, the headquarters should set the target adaptation coefficient to avoid performance manipulation on the basis of market circumstance (see Figure 2).

Furthermore, given that (21), we can find that the extent deflated performance manipulation is much more demanding when the influence of the reputation effect (reflected in $c$ ) increases (see Figure 3). The larger bargaining power coefficient $c$, which implies the more significant reputation effect in the compensation scheme, the deflated performance manipulation will be more hard to happen accompanied by increasing environmental volatility.

When $\Delta \pi_{1}^{*}=0$, the optimal pay-for-performance sensitivity is given by

$$
\beta^{*}=\frac{(1-h \delta)(1-2 c \tau \delta)+\delta}{2(\delta h-1)^{2}+2 \delta} .
$$

Proposition 8. With the existence of deflated performance manipulation, one has

$$
\begin{aligned}
& \frac{\partial \Delta \pi_{1}^{*}}{\partial \beta}>0, \\
& \frac{\partial \Delta \pi_{1}^{*}}{\partial h}>0, \\
& \frac{\partial \Delta \pi_{1}^{*}}{\partial c}<0 .
\end{aligned}
$$

This proposition shows that the extent of manipulation could be enhanced by increasing the pay-for-performance sensitivity or increasing the target adaptation coefficient or decreasing the bargaining power. The target adaptation coefficient implies the influence of the ratchet effect, the bargaining power indicates the reputation effect, and the payfor-performance sensitivity measures the relation of compensation and performance. Increasing pay-for-performance sensitivity gives a rise to the extent that the manager influences performance by manipulation and thus will also promote the manipulation. If $c \tau>\beta h$, the inhibition of the reputation effect for manipulation is superior to the motivation of the ratchet effect, and the interaction leads to lower manipulation.

\subsection{Optimal Effort Implications}

Proposition 9. If $1-h \delta>0$ (i.e., $h$ is small), the store manager will still work hard even though the pay-for-performance sensitivity $\beta$ is equal to zero. However, if $1-h \delta<0$ and

$$
\beta>\frac{c \tau \delta}{h \delta-1}
$$

the optimal effort is

$$
a_{1}^{*}=0 \text {. }
$$

Traditional static agency model result in (16) shows that the store manager makes no effort only when the payfor-performance sensitivity is equal to zero. According to 

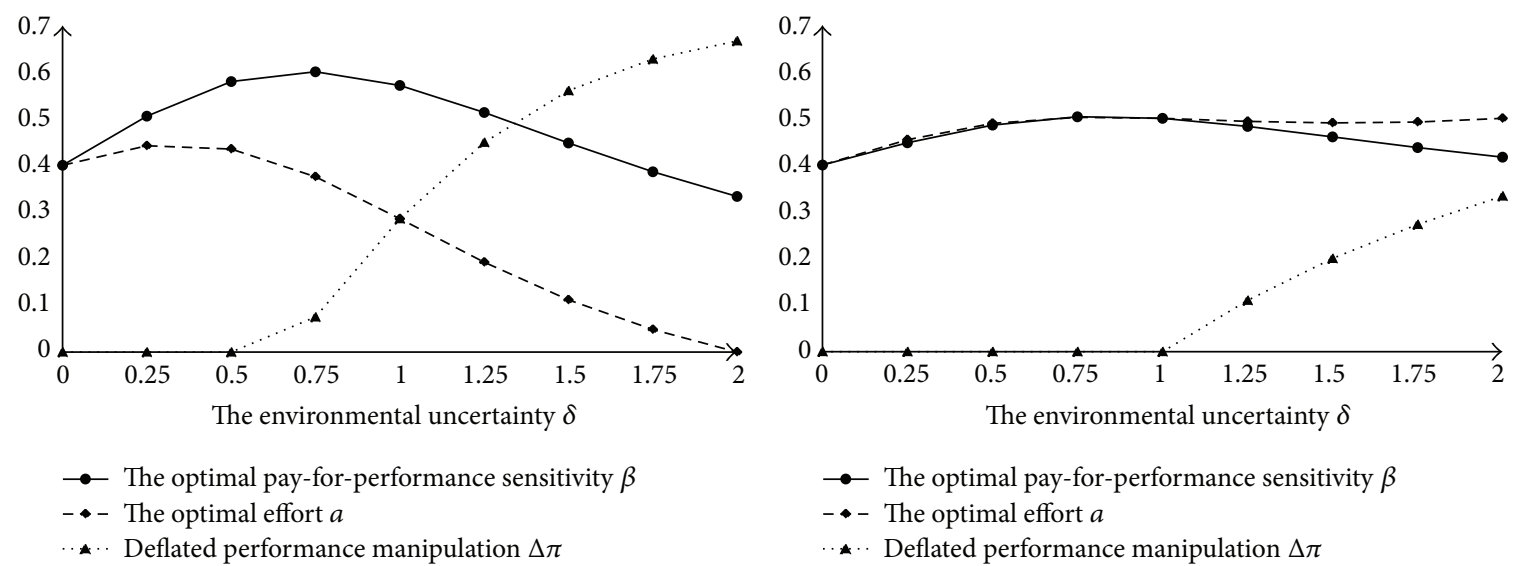

(a) The case that the bargaining power coefficient is equal to zero $(c=0)$

(b) The case that the bargaining power coefficient is equal to 0.5 $(c=0.5)$

FiguRE 3: Numerical simulations in different levels of the bargaining power coefficient and the environmental volatility. (Note that other parameters are given by $\lambda=1, \gamma=0.5, \tau=0.5, k=1, b=1$, and $h=0.5$.)

Proposition 9, however, we can draw that even if the payfor-performance sensitivity is equal to zero, the reputation effect will still motivate the manager to make effort. Thus, the positive incentive effect caused by the explicit material incentive can be partly replaced by the reputation. On the other side, in the case of a large $h$ (i.e., $h \delta-1>0$ ), even if the headquarters provides a certain amount of explicit incentives (as (24) does), the store manager instead makes no effort. This is because the managerial effort is also affected by the ratchet effect. Reducing effort leads to a lower performance target in the next period, and hence if the ratchet effect is obvious enough, potential benefits of being lazy outweigh the explicit income from being hard-working. Thus, the store manager betrays the explicit compensation and long-term implicit incentive and makes no effort.

Proposition 10. From (18), there is

$$
\begin{aligned}
& \frac{\partial a_{1}^{*}}{\partial h}<0, \\
& \frac{\partial a_{1}^{*}}{\partial c}>0 .
\end{aligned}
$$

If $1-h \delta<0$, we can draw that

$$
\frac{\partial a_{1}^{*}}{\partial \beta}<0 .
$$

Otherwise,

$$
\frac{\partial a_{1}^{*}}{\partial \beta}>0 \text {. }
$$

This proposition shows that the effort could be increased by decreasing the target adaptation coefficient or enhancing the bargaining power. If $1-h \delta<0$, the effort decreases with increasing the pay-for-performance sensitivity. In this case, the high target adaptation coefficient will enlarge the negative effect of the pay-for-performance sensitivity. Thus, different form the traditional conclusion [35], the pay-forperformance sensitivity instead leads the store manager to reduce her effort. When $c \tau>\beta h$, the motivation of the reputation effect to the managerial effort is greater than the inhibition role of the ratchet effect, and such interactive effects will lead to the higher managerial effort.

\section{Conclusions and Implications}

This paper models a dynamic agency setting regarding the game between the headquarters and its store manager of retail firms, in which the ratchet effect and the reputation effect are jointly considered to impact the store manager's deflated performance manipulation as well as effort. Hence, we investigate how the store manager balances his effort and deflated performance manipulation under the forces of such two opposite effects and suggest the cases that the store manager is likely to manipulate performance. We find that the ratchet effect and environmental volatility interactively affect the existence of deflated performance manipulation, and the reputation effect plays a role in the extent of deflated performance manipulation.

Our findings provide several managerial implications for designing incentive scheme aiming at deflated performance manipulation. First, the headquarters should master the relationship between the ratchet effect and environmental volatility to avoid the side-effect of the former. The headquarters should rationally control the ratchet effect on the basis of the evaluation of environmental circumstances. In a stable environment, a reasonable level of ratchet effect cannot lead the store manager to manipulate performance. Conversely, when facing a high environmental volatility, the deflated performance manipulation will be inevitable, and the ratchet effect will positively affect the extent of manipulation.

Second, regarding performance target setting, the headquarters should not only be based on the store manager's historical performance, but also consider the environmental 
volatility. Considering that the headquarters may be short of supervision capability as well as market insights relative to store managers, a feasible measure to evaluate a store manager's performance is by comparing her performance with both her historical and the average performance of all store managers, which can well reflect the current market circumstance. It is because that collusion across store managers seems to be impossible.

Third, the headquarters should balance the incentive power between fixed wage and pay for performance. Given that pay-for-performance sensitivity is likely to promote the store manager's performance manipulation, the headquarters can gradually enhance store managers' fixed wage to guarantee their security income in a high uncertain market environment.

Further research can be extended to study the impact of a comprehensive performance target, composed of historical and peer's performance, on the manager's performance manipulation. In addition, the store manager's social preferences, for example, loss aversion, temporal discounting, and inequity aversion, can also be incorporated into our model.

\section{Appendix}

Proof of Proposition 7. If $\delta h+\delta-1<0$, we can get

$$
\Delta \pi_{1}^{*}=\frac{(1-\gamma)[(h \delta+\delta-1) \beta-c \tau \delta]}{\gamma k}<0
$$

according to (19) in the text. Thus, the store manager will not manipulate no matter what the pay-for-performance sensitivity $\beta$ is.

While if $\delta h+\delta-1>0$, we can get that

$$
\Delta \pi_{1}^{*}=\frac{(1-\gamma)[(h \delta+\delta-1) \beta-c \tau \delta]}{\gamma k}>0,
$$

which is equivalent to

$$
\beta>\frac{c \tau \delta}{h \delta+\delta-1} .
$$

Proof of Proposition 8. With the existence of deflated performance manipulation, there is $\delta h+\delta-1>0$ and $\beta>$ $c \tau \delta /(h \delta+\delta-1)$. Hence, we can get the partial derivatives as follows according to (19):

$$
\begin{aligned}
& \frac{\partial \Delta \pi_{1}^{*}}{\partial \beta}=\frac{(1-\gamma)(h \delta+\delta-1)}{\gamma k}, \\
& \frac{\partial \Delta \pi_{1}^{*}}{\partial h}=\frac{(1-\gamma) \delta \beta}{\gamma k}, \\
& \frac{\partial \Delta \pi_{1}^{*}}{\partial c}=-\frac{(1-\gamma) \tau \delta}{\gamma k} .
\end{aligned}
$$

As all of the parameters cannot be negative in practical setting and $\gamma \leq 1$, thus we get $\partial \Delta \pi_{1}^{*} / \partial \beta>0, \partial \Delta \pi_{1}^{*} / \partial h>0$, and $\partial \Delta \pi_{1}^{*} / \partial c<0$.
Proof of Proposition 9. Based on (18), there is

$$
a_{1}^{*}=\frac{\lambda[(1-h \delta) \beta+c \tau \delta]}{b} .
$$

If $1-h \delta>0$, then

$$
a_{1}^{*}=\frac{\lambda[(1-h \delta) \beta+c \tau \delta]}{b}>0,
$$

even if the pay-for-performance sensitivity $\beta$ is equal to zero.

While if $1-h \delta<0$, then

$$
a_{1}^{*}=\frac{\lambda[(1-h \delta) \beta+c \tau \delta]}{b}<0,
$$

which is equivalent to

$$
\beta>\frac{c \tau \delta}{h \delta-1}
$$

However, the optimal effort cannot be less than zero. Thus, there is $a_{1}^{*}=0$ if $1-h \delta<0$ and $\beta>c \tau \delta /(h \delta-1)$.

Proof of Proposition 10. From (18), we can get the partial derivatives as follows:

$$
\begin{aligned}
& \frac{\partial a_{1}^{*}}{\partial h}=-\frac{\lambda \delta \beta}{b}<0, \\
& \frac{\partial a_{1}^{*}}{\partial c}=\frac{\lambda \tau \delta}{b}>0, \\
& \frac{\partial a_{1}^{*}}{\partial \beta}=\frac{\lambda(1-h \delta)}{b} .
\end{aligned}
$$

Considering the nonnegative parameters, we can get that

$$
\begin{aligned}
& \frac{\partial a_{1}^{*}}{\partial h}<0 \\
& \frac{\partial a_{1}^{*}}{\partial c}>0
\end{aligned}
$$

And when $1-h \delta<0$,

$$
\frac{\partial a_{1}^{*}}{\partial \beta}<0,
$$

otherwise,

$$
\frac{\partial a_{1}^{*}}{\partial \beta}>0
$$

\section{Competing Interests}

The authors declare that they have no competing interests.

\section{Acknowledgments}

This work is supported by the National Natural Science Foundation of China (Grant nos. 71272064 and 71121061) and the Science and Technological Fund of Anhui Province for Outstanding Youth (Grant no. 1308085JGD07). 


\section{References}

[1] A. Beyer, I. Guttman, and I. Marinovic, "Optimal contracts with performance manipulation," Journal of Accounting Research, vol. 52, no. 4, pp. 817-847, 2014.

[2] G. P. Cachon and M. A. Lariviere, "Supply chain coordination with revenue-sharing contracts: strengths and limitations," Management Science, vol. 51, no. 1, pp. 30-44, 2005.

[3] J. E. Villegas, E. M. Gonzalez, M. P. Gonzalez, J. V. Anguita, and J. L. Vicent, "Experimental ratchet effect in superconducting films with periodic arrays of asymmetric potentials," Physical Review B, vol. 71, no. 2, Article ID 024519, 2005.

[4] B. W. Ickes and L. Samuelson, "Job transfers and incentives in complex organizations: thwarting the ratchet effect," The RAND Journal of Economics, vol. 18, no. 2, pp. 275-286, 1987.

[5] J. P. Choi and M. Thum, "The dynamics of corruption with the ratchet effect," Journal of Public Economics, vol. 87, no. 3-4, pp. 427-443, 2003.

[6] X. Freixas, R. Guesnerie, and J. Tirole, "Planning under incomplete information and the ratchet effect," The Review of Economic Studies, vol. 52, no. 2, pp. 173-191, 1985.

[7] M. L. Weitzman, "The 'ratchet principle' and performance incentives," The Bell Journal of Economics, vol. 11, no. 1, pp. 302308,1980 .

[8] J. Bouwens and P. Kroos, "Target ratcheting and effort reduction," Journal of Accounting and Economics, vol. 51, no. 1, pp. 171-185, 2011.

[9] E. F. Fama, "Agency problems and the theory of the firm," The Journal of Political Economy, vol. 88, no. 2, pp. 288-307, 1980.

[10] P. M. Healy, "The effect of bonus schemes on accounting decisions," Journal of Accounting and Economics, vol. 7, no. 1-3, pp. 85-107, 1985.

[11] J. J. Gaver, K. M. Gaver, and J. R. Austin, "Additional evidence on bonus plans and income management," Journal of Accounting and Economics, vol. 19, no. 1, pp. 3-28, 1995.

[12] A. M. Goel and A. V. Thakor, "Why do firms smooth earnings?" The Journal of Business, vol. 76, no. 1, pp. 151-192, 2003.

[13] R. W. Holthausen, D. F. Larcker, and R. G. Sloan, "Annual bonus schemes and the manipulation of earnings," Journal of Accounting and Economics, vol. 19, no. 1, pp. 29-74, 1995.

[14] K. J. Crocker and J. Morgan, "Is honesty the best policy? Curtailing insurance fraud through optimal incentive contracts," Journal of Political Economy, vol. 106, no. 2, pp. 355-375, 1998.

[15] E. Goldman and S. L. Slezak, "An equilibrium model of incentive contracts in the presence of information manipulation," Journal of Financial Economics, vol. 80, no. 3, pp. 603-626, 2006.

[16] N. Burns and S. Kedia, "The impact of performance-based compensation on misreporting," Journal of Financial Economics, vol. 79, no. 1, pp. 35-67, 2006.

[17] K. J. Crocker and J. Slemrod, "The economics of earnings manipulation and managerial compensation," The RAND Journal of Economics, vol. 38, no. 3, pp. 698-713, 2007.

[18] R. J. Indjejikian, M. Matějka, K. A. Merchant, and W. A. Van Der Stede, "Earnings targets and annual bonus incentives," The Accounting Review, vol. 89, no. 4, pp. 1227-1258, 2014.

[19] S. Baiman, J. H. Evans III, and J. Noel, "Optimal contracts with a utility-maximizing auditor," Journal of Accounting Research, vol. 25, no. 2, pp. 217-244, 1987.

[20] R. A. Dye, "Earnings management in an overlapping generations model," Journal of Accounting Research, vol. 26, no. 2, pp. 195-235, 1988.
[21] J. S. Demski, "Performance measure manipulation," Contemporary Accounting Research, vol. 15, no. 3, pp. 261-285, 1998.

[22] M. D. Rablen, "Performance targets, effort and risk-taking," Journal of Economic Psychology, vol. 31, no. 4, pp. 687-697, 2010.

[23] A. J. Leone and S. Rock, "Empirical tests of budget ratcheting and its effect on managers' discretionary accrual choices," Journal of Accounting and Economics, vol. 33, no. 1, pp. 43-67, 2002.

[24] S. Roychowdhury, "Earnings management through real activities manipulation," Journal of Accounting and Economics, vol. 42, no. 3, pp. 335-370, 2006.

[25] L. G. Eldenburg, K. A. Gunny, K. W. Hee, and N. Soderstrom, "Earnings management using real activities: evidence from nonprofit hospitals," The Accounting Review, vol. 86, no. 5, pp. 1605-1630, 2011.

[26] P. H. Dybvig, "Dusenberry's ratcheting of consumption: optimal dynamic consumption and investment given intolerance for any decline in standard of living," The Review of Economic Studies, vol. 62, no. 2, pp. 287-313, 1995.

[27] B. Holmstrom, "Equilibrium long-term labor contracts," The Quarterly Journal of Economics, vol. 98, pp. 23-54, 1983.

[28] M. A. Meyer and J. Vickers, "Performance comparisons and dynamic incentives," Journal of Political Economy, vol. 105, no. 3, pp. 547-581, 1997.

[29] M. J. Dollinger, P. A. Golden, and T. Saxton, "The effect of reputation on the decision to joint venture," Strategic Management Journal, vol. 18, no. 2, pp. 127-140, 1997.

[30] K. Weigelt and C. Camerer, "Reputation and corporate strategy: a review of recent theory and applications," Strategic Management Journal, vol. 9, no. 5, pp. 443-454, 1988.

[31] M. Spence and R. Zeckhauser, "Insurance, information, and individual action," The American Economic Review, vol. 61, no. 2, pp. 380-387, 1971.

[32] J. A. Mirrlees, "The optimal structure of incentives and authority within an organization," The Bell Journal of Economics, vol. 7, no. 1, pp. 105-131, 1976.

[33] B. Holmstrom, "Moral hazard and observability," The Bell Journal of Economics, vol. 10, no. 1, pp. 74-91, 1979.

[34] S. J. Grossman and O. D. Hart, "An analysis of the principalagent problem," Econometrica. Journal of the Econometric Society, vol. 51, no. 1, pp. 7-45, 1983.

[35] M. L. Weitzman, "Efficient incentive contracts," The Quarterly Journal of Economics, vol. 94, no. 4, pp. 719-730, 1980.

[36] B. Holmstrom and P. Milgrom, "Aggregation and linearity in the provision of intertemporal incentives," Econometrica. Journal of the Econometric Society, vol. 55, no. 2, pp. 303-328, 1987.

[37] O. Hart and B. Holmstrom, The Theory of Contracts, Department of Economics, Massachusetts Institute of Technology, 1986.

[38] B. Holmström, "Managerial incentive problems: a dynamic perspective," The Review of Economic Studies, vol. 66, no. 1, pp. 169-182, 1999.

[39] L. Martinez, Reputation and Career Concerns, Federal Reserve Bank of Richmond, 2006.

[40] D. Gill and R. Stone, "Fairness and desert in tournaments," Games and Economic Behavior, vol. 69, no. 2, pp. 346-364, 2010.

[41] D. Xing and T. Liu, "Sales effort free riding and coordination with price match and channel rebate," European Journal of Operational Research, vol. 219, no. 2, pp. 264-271, 2012. 


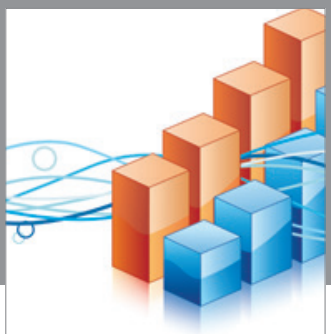

Advances in

Operations Research

vatem alat4

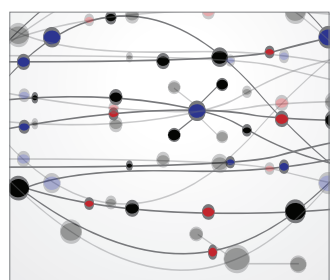

\section{The Scientific} World Journal
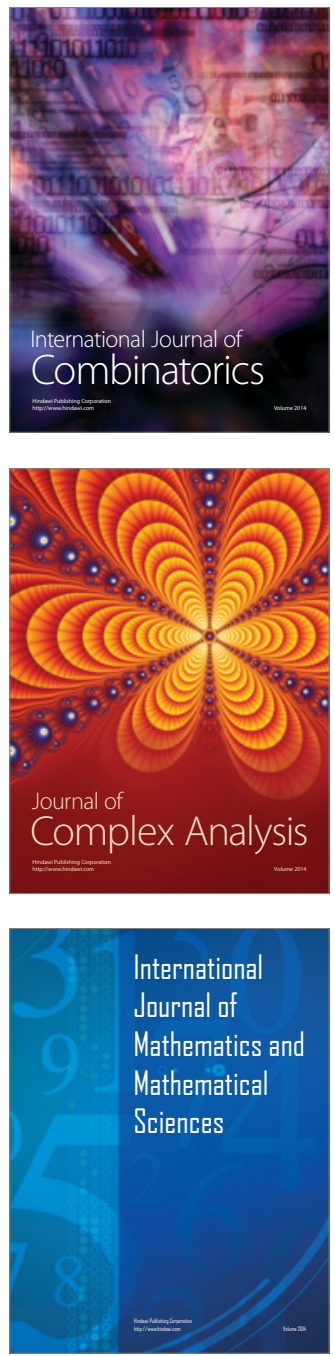
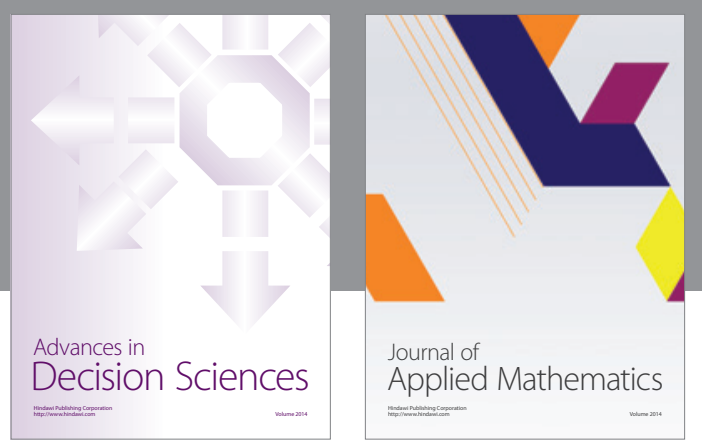

Algebra

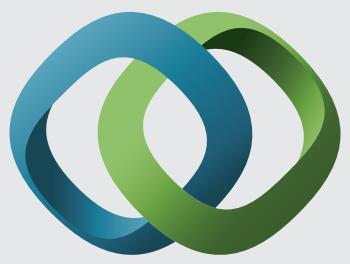

\section{Hindawi}

Submit your manuscripts at

http://www.hindawi.com
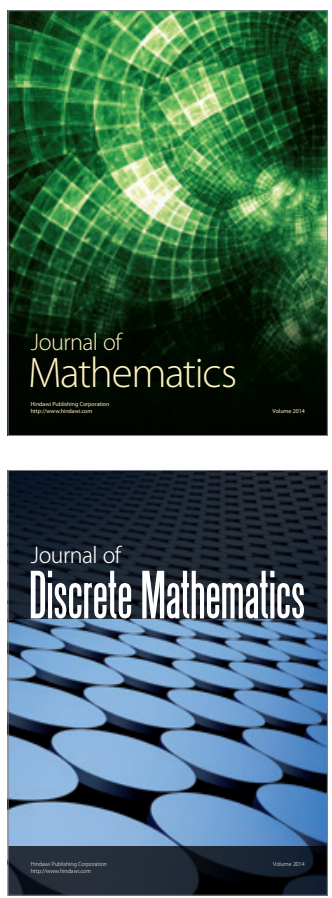

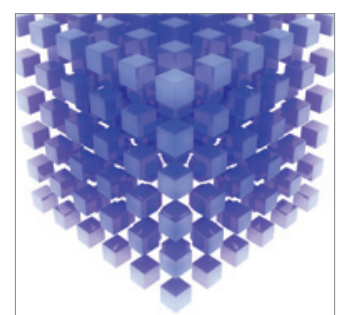

Mathematical Problems in Engineering
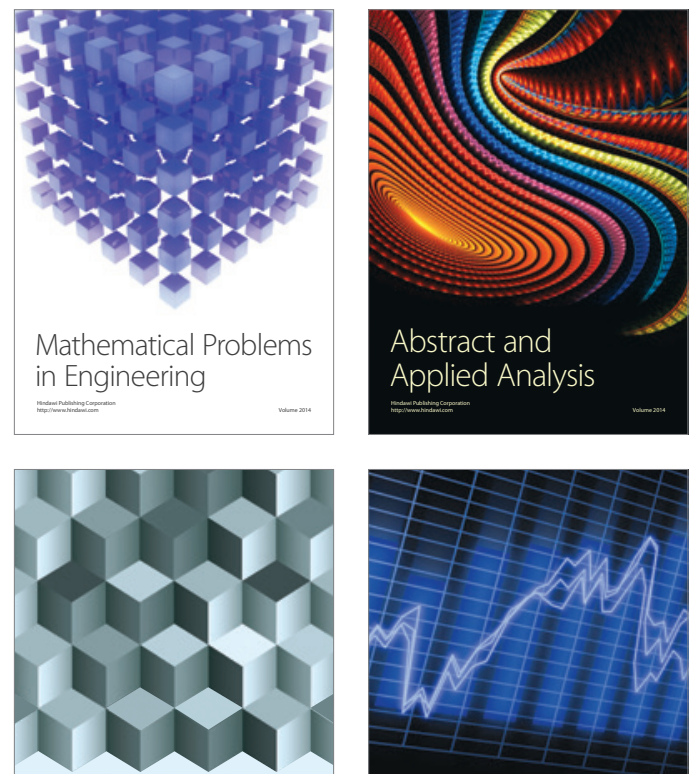

Journal of

Function Spaces

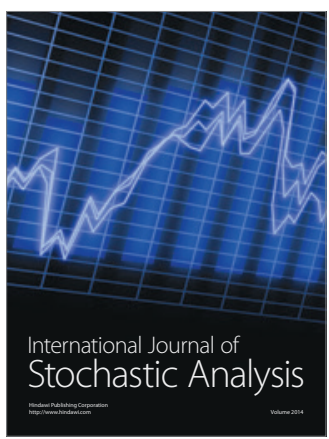

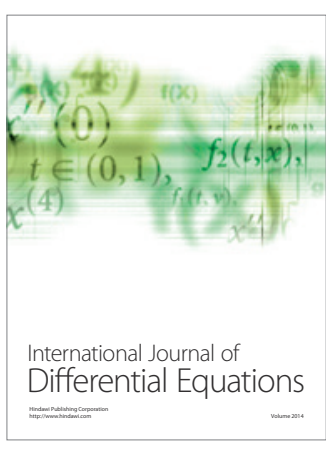
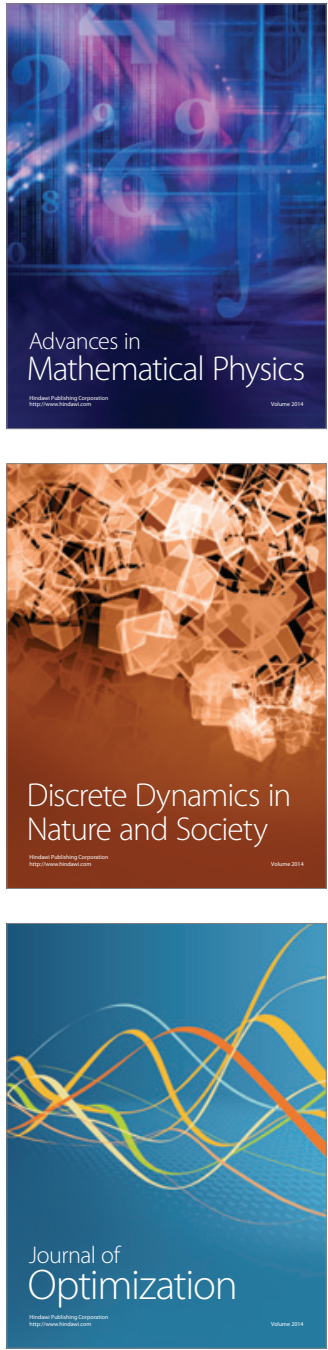